\title{
Indicios de pastoreo extensivo en el noroeste peninsular durante el dominio suevo
}

PÉREZ-RAMA, M. ${ }^{1}$, VAQUEIRO RODRÍGUEZ, M. ${ }^{1,2}$ y GRANDAL-D'ANGLADE, A. ${ }^{1,2 *}$

(1) Instituto Universitario de Xeoloxía "Isidro Parga Pondal". Universidade da Coruña. 15071 A Coruña.

(2) Clube de Espeleoloxía A Trapa (CETRA).

*aurora.grandal@udc.es

https://doi.org/10.17979/cadlaxe.2015.38.0.3686

\section{Resumen:}

Las condiciones edáficas de Galicia (NW de España), debido al sustrato ácido predominante, dificultan la conservación de los restos arqueozoológicos asociados a los asentamientos humanos. En estos casos, la búsqueda en zonas alternativas, como cuevas y trampas naturales en las zonas de pastoreo, puede aportar información sobre los recursos animales disponibles.

Se presenta aquí un estudio de los restos de ganado vacuno doméstico encontrados en Cova da Tara o Tara da Triega (Serra do Courel, Lugo). Con una edad de alrededor de 1500 años, los huesos corresponderían a la época de la dominación sueva del Noroeste peninsular. Estos animales habrían llegado vivos a la cueva, de donde se deduce que deambulaban libremente en los alrededores, lo que señala un tipo de pastoreo extensivo. El desgaste dentario y el estudio de isótopos estables en el colágeno óseo reflejan una alimentación poco abrasiva, probablemente arbustiva, concordando con la de zonas de montaña. La talla media calculada para estos animales es pequeña, similar a la descrita para ganado vacuno prerromano.

Palabras clave: Manejo de ganado, Alta Edad Media, Galicia, isótopos estables, desgaste dental. 


\begin{abstract}
:
The soil conditions in Galicia (NW of Spain), due to the predominant acid substrate, makes difficult the conservation of archaeozoological remains associated with human settlements. In these cases, the search for alternative areas, such as caves and natural traps in pasturelands, can provide information on the animal resources available.

We present here a study about domestic cattle remains found in Cova da Tara or Tara da Triega (Serra do Courel, Lugo), with an age of about 1500 years BP. The bone remains were laid at the time of the Swabian domination of peninsular northwest. These animals would come alive to the cave, from which it follows that roamed freely around, indicating an extensive livestock management. The tooth wear and the study of stable isotopes in bone collagen reflect a little abrasive diet, probably shrub, matching the vegetation of mountain areas. The average height calculated for these animals is small, similar to that described for pre-Roman cattle.
\end{abstract}

Keywords: livestock management, High Middle Ages, Galicia, stable isotopes, dental wear. 


\section{INTRODUCCIÓN.}

Ya sea centrándose en los restos descartados del consumo y preparación de alimentos, animales empleados para el trabajo y como compañía, o señales de prácticas religiosas y funerarias, la mayoría de estudios zooarqueológicos suelen estar asociados a lugares de asentamiento, industria o enterramiento humanos. En Galicia, el tipo de geología existente en la mayor parte de su territorio, en la que el alto $\mathrm{pH}$ favorece una rápida destrucción de los restos orgánicos (Grandal d'Anglade et al., 1997), representa una dificultad para la obtención de restos animales en este tipo de contextos arqueológicos. Sin embargo, la zooarqueología es un necesario complemento a otro tipo de aproximaciones al estudio del pasado de los seres humanos, permitiendo una mejor comprensión de su economía, hábitos, intereses y recursos disponibles, siendo estos estudios fundamentales para comprender la historia de los animales domésticos, y cómo ha variado tanto su morfología como su función a lo largo del tiempo.

En las zonas kársticas de Galicia, hasta no hace mucho e incluso hoy en día de forma ocasional, las cuevas se han usado como refugios improvisados, almacenes o lugares de eliminación de desperdicios, incluyendo animales débiles o enfermos. Alejadas a veces kilómetros de las viviendas más cercanas, estas formaciones naturales son sin embargo conocidas y utilizadas por la gente de la región. Esto no representa ninguna contradicción ya que en un entorno rural, incluso antes del uso generalizado de transportes motorizados, las personas aprovechaban recursos de una zona relativamente amplia, y no tan sólo los lugares inmediatamente adyacentes a sus viviendas: los bosques eran una fuente de madera, caza y ciertos alimentos como las castañas o las bellotas y las zonas de pastoreo y las tierras de labor no siempre están en los mismos terrenos que las viviendas. La actividad que se produce en estas zonas, alejadas de estructuras humanas, no suele ser objeto de estudio de la arqueología, ya que las señales que podrían dejar, como por ejemplo los cambios en la vegetación y el suelo debido a talas, desbroces o actividad de rebaños de animales, senderos de acceso abiertos o incluso ciertos tipos de delimitaciones, como la plantación de hileras de árboles y arbustos, suelen desaparecer, o hacerse mucho más difíciles de detectar su presencia con el paso del tiempo, Sin embargo, eso no significa que todas las huellas hayan desaparecido. El interior de las cuevas, por su ambiente estable que facilita la conservación de los restos, y su disponibilidad para haber sido usadas como refugio temporal, puede aportar información complementaria a la disponible en otros tipos de yacimientos más tradicionales.

Los materiales aquí tratados se corresponden con restos animales recogidos en Cova da Tara, en la Serra do Courel (Figura 1), un sistema glaciar cuaternario fósil que coincide con una zona cárstica. En O Courel se pueden encontrar las huellas de un glaciarismo de tipo alpino ocurrido durante la última fase glaciar pleistocena, que cubrió la zona con un casquete de unos 65 km2 (Vidal Romaní et al., 1992). Durante los momentos de glaciarismo la entrada de la cueva se situaba por debajo del nivel de los hielos, por lo que el acceso a la cueva sólo pudo producirse una vez que las condiciones climáticas fueran favorables, imponiendo una restricción temporal a los restos que allí se encuentran. 


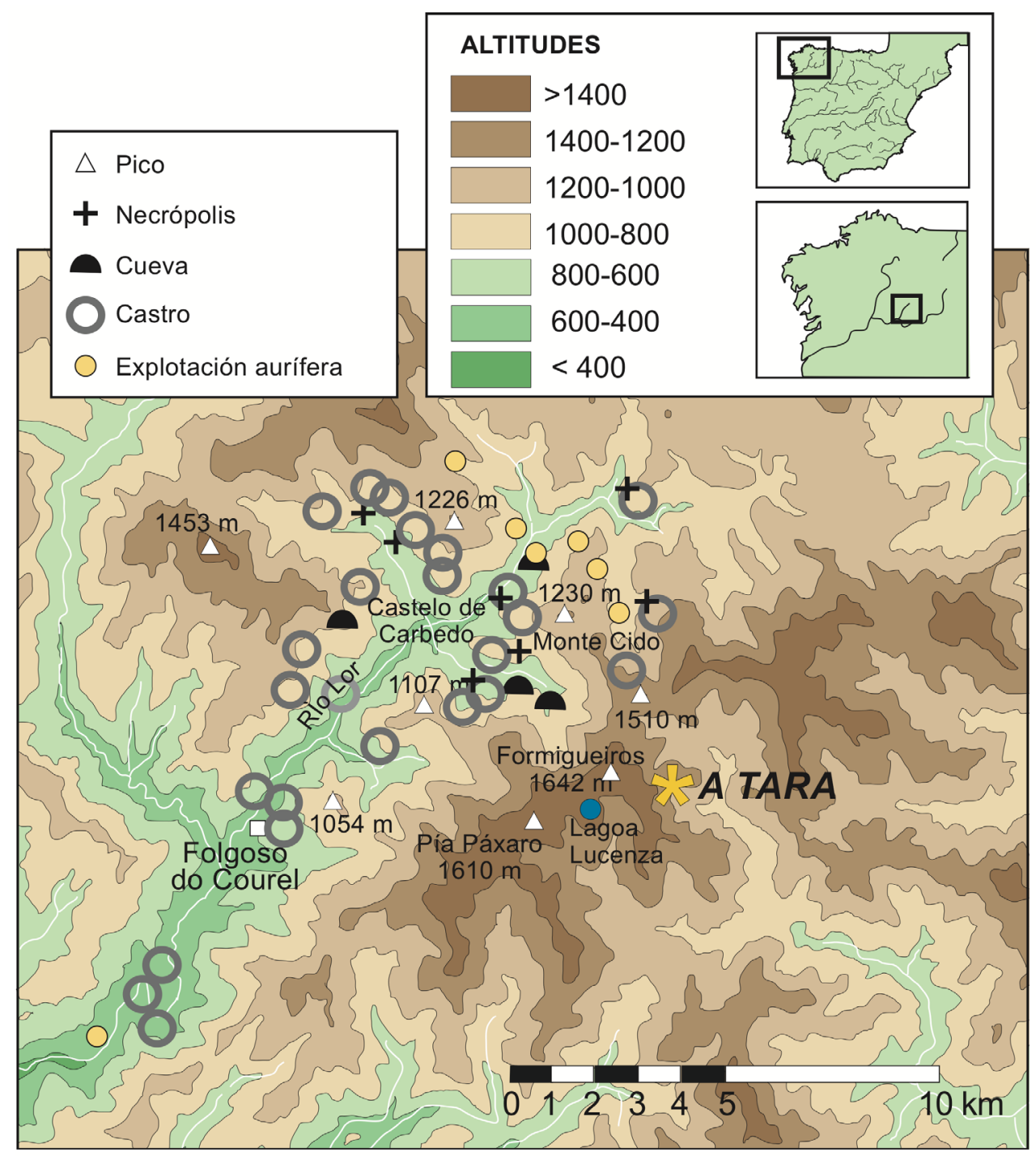

Fig. 1. Localización de la cueva de A Tara, y principales yacimientos arqueológicos descritos en las inmediaciones. 
Si bien no hay restos de edificaciones de épocas medieval, romanas o castreñas en el entorno inmediato de la cueva, ni se han encontrado útiles o restos de origen humano en su interior, sí existen abundancia de construcciones arquitectónicas y restos arqueológicos de estas épocas en las zonas cercanas (Luzón Nogué et al., 1980). Tomando tan sólo un radio de $10 \mathrm{~km}$ alrededor de la cueva, podemos encontrar el Castillo medieval de Carbedo, construido probablemente sobre el asentamiento de un antiguo castro, el Monte Cido, en cuya necrópolis se encontraron una tabla de hospitalidad del año $28 \mathrm{dC}$ y un águila romana de bronce, así como un buen número de castros y lugares de explotación aurífera, junto con señales del trazado de antiguas vías de comunicación que unían entre sí las poblaciones y los lugares de extracción de mineral. Los trabajos de intensa explotación aurífera llevados a cabo por los romanos, según Luzón Nogué et al. (1980), habrían provocado la movilización hacia la zona de un gran número de personas, que probablemente aprovecharían los asentamientos castreños. Existen indicios aún más antiguos de presencia humana en la zona. En otra cueva próxima, A Cova do Oso, se encontraron restos de cerámica que fueron datados, debido a su estilo, entre el principio de la Edad de Bronce y principios de la del Hierro (Luzón Nogué et al., 1980). No es aventurado, entonces, suponer la existencia de poblaciones relativamente cercanas a la cueva entre la época romana y medieval, pudiendo haber sido la zona visitada, bien fuera de manera regular u ocasional, incluso no existiendo asentamientos humanos asociados directamente a la cueva. Sin olvidar además, que la llegada de los suevos no significó el abandono de los castros, que siguieron teniendo actividad durante esa época (Díaz Martínez, 1983),

La entrada de la cueva está constituida por una estrecha abertura en el suelo en forma de embudo (Figura 2), que conecta con una galería descendiente en rampa de pendiente media $-47^{\circ}$. Aproximadamente a $-14 \mathrm{~m}$ de profundidad termina en una serie de escalones abruptos hasta alcanzar la entrada de la sala principal, que se desarrolla entre los -26 y los $-37 \mathrm{~m}$ de profundidad, por lo que es necesario ayudarse de material de progresión vertical (posicionamiento y acceso mediante técnicas de cuerda) para poder superar con seguridad estos desniveles, en los que la arcilla, húmeda y resbaladiza, dificulta encontrar asidero. 

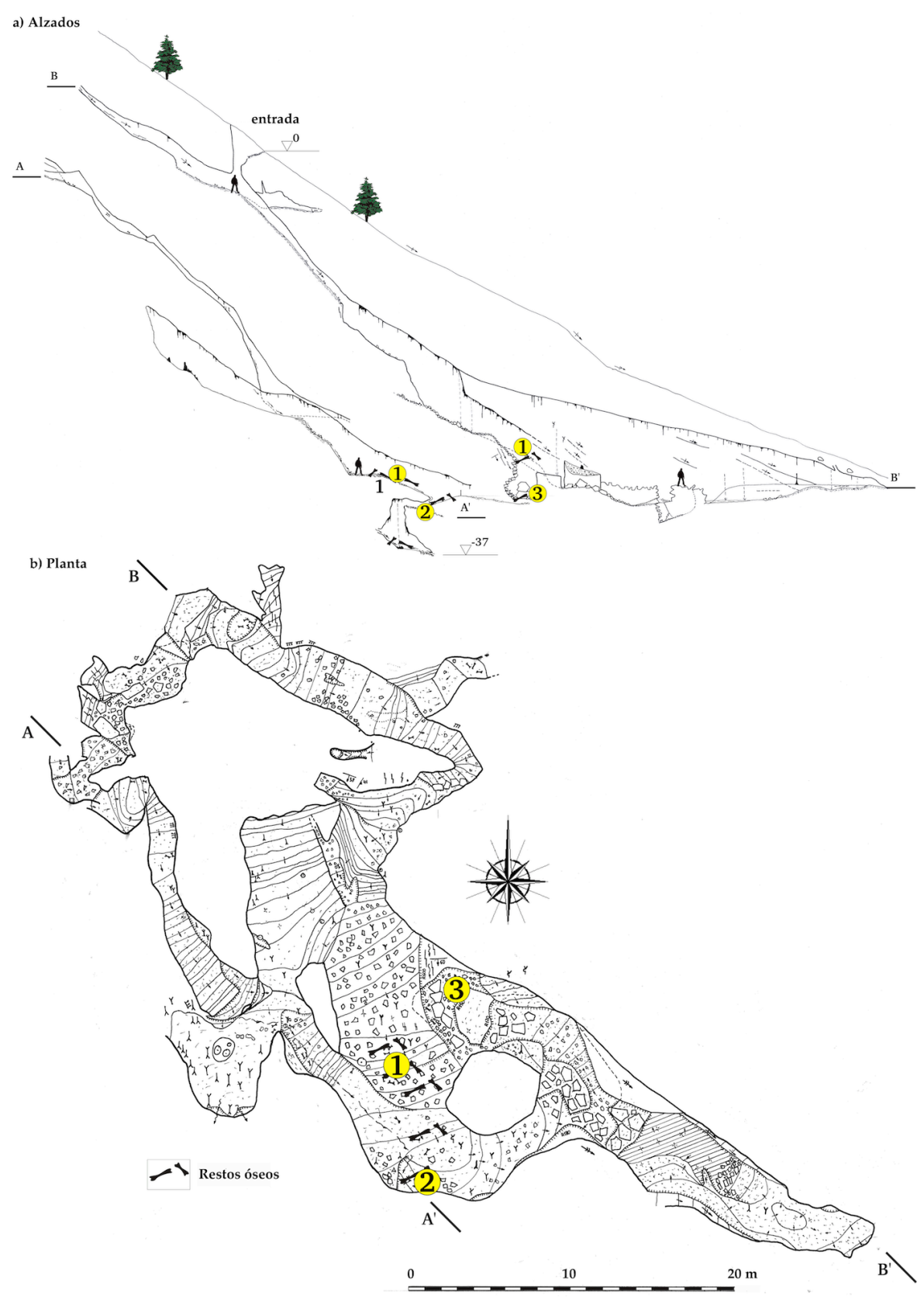

Fig. 2. Topografía (a) y perfil (b) de Cova da Tara. Los números señalan las zonas donde se recogió material. Cartografía elaborada sobre la topografía base incluida en Vaqueiro (2007). 
Las dimensiones de la boca, que queda fácilmente oculta por la nieve (Figura 3a), y la topografía en rampa-pozo, hacen que la cueva funcionase como trampa natural.

Animales en busca de refugio o que cayesen a través de la entrada en situaciones de baja visibilidad, como las que podría provocar la lluvia o la nieve, descenderían prácticamente en caída libre hasta los -26 m, donde, además de sufrir las consecuentes lesiones, encontrarían grandes dificultades en subir de nuevo a la superficie por sus propios medios, mientras que, una vez dentro, si optasen por vagabundear en busca de otra salida, la falta de luz y la topografía de la cueva les haría difícil orientarse.

Los efectos de la gravedad tienen gran importancia en la cueva. En las zonas de menor pendiente existen acumulaciones de cantos (Figura 3b), resultados de procesos de desprendimiento. Los restos óseos se han localizado en la zona baja de la sala principal, o al pie de los distintos escarpes en los que se configura la sala. Algunos huesos están cubiertos por los cantos y posiblemente se habrían desplazado con los materiales del depósito durante su caída (Figura 3c). Sin embargo, también se han encontrado esqueletos en posición original.
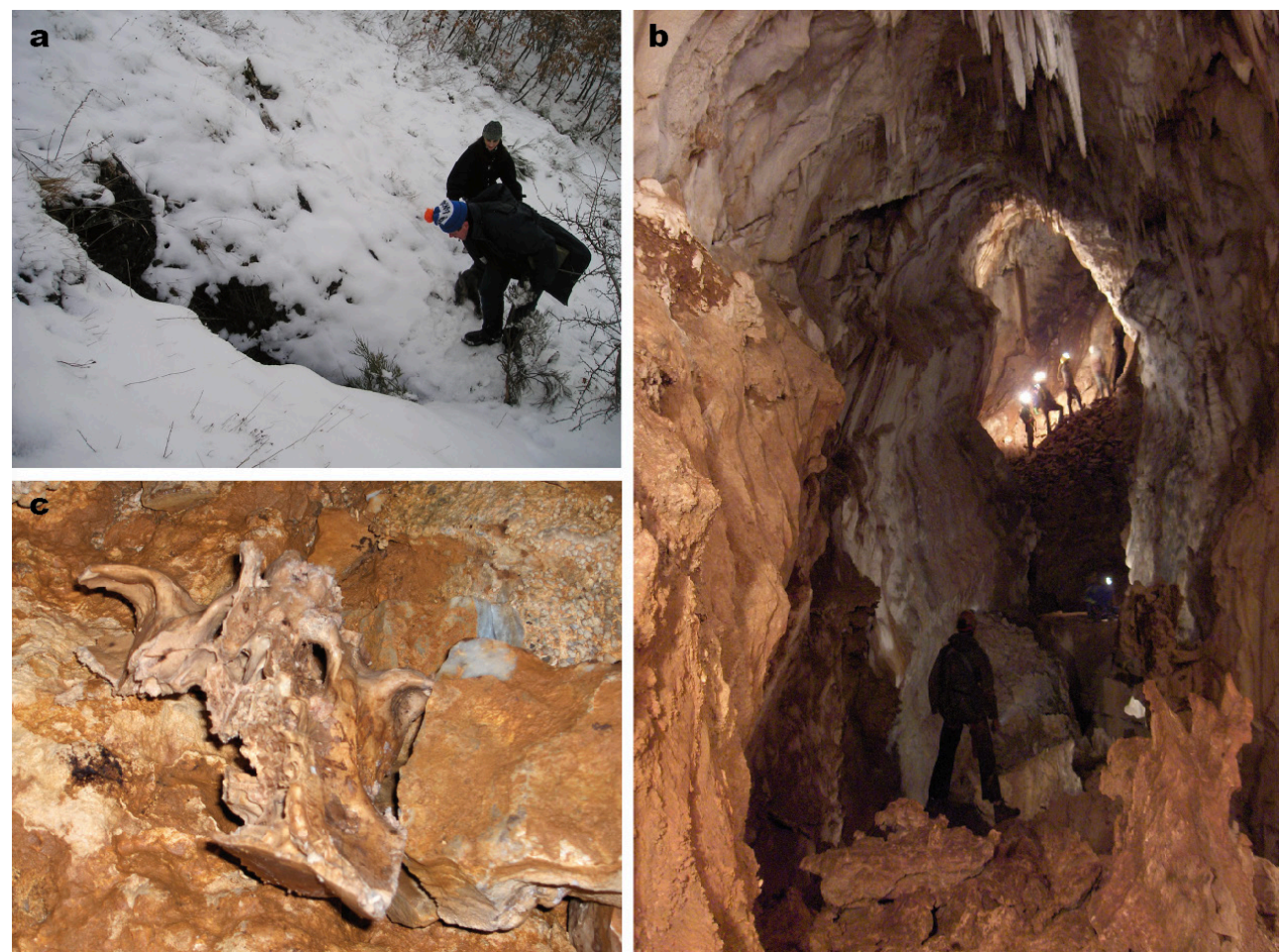

Fig. 3. Vista del exterior de la entrada a la cueva durante el invierno (a) e interior de Cova da Tara (b), mostrando la fuerte pendiente con rocas procedentes de desprendimientos y la forma de acumulación de ese material. Detalle de resto óseo in situ (c). Fotografías: M. Vaqueiro. 


\section{MATERIAL Y MÉTODOS.}

En la topografía de la cueva (Figura 2) se señalan las zonas de trabajo con presencia de restos óseos. Los restos tratados aquí se extrajeron de las zonas señaladas como 1 y 2 . También se recuperaron restos en la zona 3.

Excepto una hemimandíbula de lagomorfo, todos los materiales identificados en las zonas señaladas corresponden a artiodáctilos, en la mayoría pertenecientes a especies domésticas, en concreto, vaca (Bos taurus L.) y ovicaprino, aunque también fueron recuperados algunos fragmentos óseos de ciervo (Cervus elaphus L.). Asociados a las zonas de trabajo no se encontraron restos de depredadores o animales carroñeros u omnívoros, como podrían ser perros o lobos, aunque existiesen poblaciones de estos animales en la zona. En la cueva sí se encontró un único hueso de oso pardo (Ursus arctos L.), aunque no estaba asociado a las zonas indicadas, habiéndose datado en $2535 \pm 40$ años BP (García-Vázquez et al., 2011), por lo que su cronología, como se verá más adelante, es anterior a los animales domésticos aquí tratados.

Los restos de ganado bovino y ciervo fueron recuperados en su mayoría en la zona 1, aunque algunos de ellos estaban en el punto 2, al que habían llegado rodando junto con rocas y otros sedimentos. La zona 3 indica un segundo punto de recogida de restos, en la que se recuperaron varios restos de ovicápridos. Otros restos puntuales de ovicápridos fueron recogidos en otras zonas de la cueva. Al no disponer de datación para estas especies, no se incluyen en este trabajo.

Cova da Tara presenta una morfología que impide llevar a cabo la recolección de muestras en condiciones óptimas, ya que no se pudo disponer una cuadrícula y establecer divisiones por cuadrantes. Así mismo, debido a la pendiente y estrechez de la galería de acceso en la actualidad y lo escarpado del terreno en ciertos puntos, es difícil extraer las muestras y llevarlas al exterior, por lo que se produjeron algunas fracturas en el material durante el proceso. La recolección no fue exhaustiva, limitándose la recuperación de restos en superficie, sin remoción de sedimentos.

La toma de medidas de los restos se realizó según el protocolo de Von Den Driesch (1976), utilizando calibres electrónicos de precisión $0,01 \mathrm{~mm}$, excepto en el caso de las longitudes máximas de los huesos largos, para lo que se usó un tablero osteométrico de precisión $0,5 \mathrm{~mm}$.

Los restos identificados que estaban en un mejor estado de conservación permitieron realizar el cálculo de la altura del animal siguiendo los Factores de Fock y Matolcsi, en el caso de los bóvidos (según aparecen reflejados en Altuna, 1980).

Nueve restos de costilla de vaca doméstica fueron analizados para obtener el valor isotópico de carbono y nitrógeno en colágeno óseo. La extracción de colágeno se realizó en el Instituto Universitario de Xeoloxía de la UDC siguiendo el método de Bocherens et al., (1997). La limpieza de la muestra se realizó en baños repetidos en acetona y agua destilada en cubeta de ultrasonidos, empleándose posteriormente $\mathrm{HCl}$ sobre la muestra ya reducida a polvo para eliminar el carbono inorgánico y $\mathrm{NaOH}$ para evitar las posibles contaminaciones de ácidos orgánicos. El colágeno extraído, tras permanecer la muestra en $\mathrm{HCl} 0,01 \mathrm{M}$ a $100^{\circ}$ durante 17 horas, fue liofilizado, realizándose su determinación isotópica en los Servicios de Apoyo a la Investigación de la UDC. Los valores isotópicos obtenidos se expresan 
según la notación delta $(\delta)$, que indica la desviación con respecto a un estándar en la proporción entre isótopo pesado y ligero. Los estándares utilizados fueron los habituales: la caliza PDB para el carbono y el Nitrógeno atmosférico para el nitrógeno.

\section{RESULTADOS Y DISCUSIÓN.}

\subsection{Estudio faunístico.}

En la zona 1 y 2 se recuperaron un total de 429 fragmentos, que, una vez reconstruidos arrojan un total de 260 restos de Bos taurus, 5 de otras especies, y 151 fragmentos no identificables. Los restos óseos de Bos taurus se relacionan en la tabla 1 . Se excluyen del listado las piezas pertenecientes a otras especies: una hemimandíbula de lagomorfo (Oryctolagus cuniculus), un escafocuboide de ovicáprido fusionado con un gran cuneiforme, fusión que quizás se debiera a algún proceso patológico, y tres piezas pertenecientes a ciervo (Cervus elaphus): un fragmento de asta, una primera falange y un fragmento de pelvis.

\begin{tabular}{|c|c|c|c|}
\hline Cráneo & 36 & Dentición: & \\
\hline \multirow[t]{2}{*}{ Mandíbula } & 7 & INFERIOR & \\
\hline & & Incisivos & 4 \\
\hline Vértebras: & & Segundo Premolar & 2 \\
\hline Axis & 2 & Tercer Premolar & 2 \\
\hline V. Cervicales & 9 & Primer Molar & 3 \\
\hline V. Torácicas & 13 & Segundo Molar & 2 \\
\hline V. Lumbares & 3 & Tercer Molar & 3 \\
\hline V. Caudales & 1 & SUPERIOR & \\
\hline \multirow[t]{2}{*}{ Indeterminables } & 21 & Segundo Premolar & 1 \\
\hline & & Tercer Premolar & 2 \\
\hline \multirow[t]{4}{*}{ Costillas } & 80 & Cuarto Premolar & 3 \\
\hline & & Primer Molar & 3 \\
\hline & & Segundo Molar & 3 \\
\hline & & Tercer Molar & 3 \\
\hline Escápula & 5 & Pelvis & 6 \\
\hline Humero & 5 & Fémur & 3 \\
\hline Ulna & 4 & Rótula & 4 \\
\hline Radio & 4 & Tibia & 4 \\
\hline Carpo: & & Tarso: & \\
\hline Piramidal & 1 & Astrágalo & 2 \\
\hline
\end{tabular}




\begin{tabular}{|c|c|c|c|}
\hline Cabezo-trapezoidal & 2 & Calcáneo & 2 \\
\hline Ganchudo & 1 & Escafo-cuboides & 2 \\
\hline & & Gran Cuneiforme & 1 \\
\hline Metacarpo & 2 & Metatarso & 2 \\
\hline Falanges: & & & \\
\hline${\text { Falange } \mathbf{1}^{\mathbf{a}}}^{\text {Falange } \mathbf{2}^{\mathbf{a}}}$ & 4 & & \\
\hline${\text { Falange } \mathbf{3}^{\mathbf{a}}}^{\text {Total : } \mathbf{2 6 0}}$ & 2 & & \\
\hline
\end{tabular}

Tabla 1. Número de restos de Bos taurus encontrados en las zonas 1 y 2

De los materiales recuperados en la zona 1 y 2, la ulna de Bos taurus CT-304 fue datada mediante el método $\mathrm{AMS}^{14} \mathrm{C}$, que ofrece la ventaja de permitir obtener la datación a partir de muestras muy pequeñas. La datación fue realizada en el Tandem Laboratoriet de la Universidad de Uppsala, asignándosele el número de análisis Ua-24251. Los resultados arrojaron una edad de $1600 \pm$ 40 años BP. La edad calibrada es de $1488 \pm$ 52 Cal BP (Fairbanks et al., 2005), que la sitúan entre los años 410 y $585 \mathrm{dC}$, coincidiendo con el Reino Suevo en Galicia.

\subsection{Consideraciones tafonómicas.}

Aunque se ha datado directamente una de las piezas encontradas, debido a que existen distintas zonas de acumulación de los restos y no pudiendo reconocerse estratos de deposición de sedimentos, no es posible establecer una relación cronológica entre la fauna presente en toda la cueva, por lo que no es posible conocer la cronología de toda la fauna. Mientras que en la zona 2, debido a la pendiente y configuración, se encuentran huesos arrastrados desde puntos situados más arriba, y restos del mismo animal pueden encontrarse repartidos entre la zona 1 y 2 , no ocurre lo mismo con la zona 3 , donde la dinámica natural de la cueva habría transportado los restos óseos a otras zonas sin que haya relación entre la acumulación entre las zonas 1y 2 y los restos obtenidos en el punto 3. Por ello los restos óseos de la zona 3 , pertenecientes todos ellos a ovicápridos, no se incluyen en este estudio.

La tabla 1 refleja el número de restos óseos de Bos taurus, pero teniendo en cuenta las condiciones de la cueva, es de destacar que ciertos factores influirían en las diferencias entre el número de restos recuperados respecto a los depositado inicialmente. Aunque hay muchas piezas relativamente bien conservadas, los desprendimientos de rocas provocan la fragmentación (y en algunos casos, aplastamiento) de los restos, lo que origina una sobrerrepresentación de algunas partes del esqueleto. Aunque fue posible reconstruir los huesos largos, al menos en parte, los fragmentos de cráneo, costillas o vertebras presentaban más dificultades.

Al estudiar los restos de Bos taurus se llegó a la conclusión de que pertenecían únicamente a 2 individuos, en lugar de ser una acumulación de restos variados de in- 
dividuos distintos. En primer lugar, aunque de cada parte esquelética concreta hay poca representación, se han recuperado fragmentos o huesos completos de casi todas las partes esqueléticas. La proporción en que se han encontrado es similar a la que existe en el esqueleto completo, y no parece haber habido ningún tipo de proceso de selección como el que podría producirse si los animales hubiesen sido consumidos por carnívoros o troceados por seres humanos (Figura 4). Por otra parte, aunque algunos de los huesos presentan marcas de roedores, no se han encontrado huellas antrópicas, como marcas de corte o quemado, ni tampoco señales dejadas por carnívoros. Algunos de los huesos, además, estaban en suficiente buen estado de conservación para que fuese posible incluso articular algunas de las extremidades de los animales. Aunque existió movimiento por gravedad de algunas de las piezas debido a la pendiente en la zona 1, los huesos desplazados por este motivo lo hicieron a lo largo de la pendiente hasta acumularse en la zona 2 , de donde fueron recuperados, por lo que este transporte no determinó una pérdida importante de restos. Las únicas desviaciones importantes del número de restos de bóvido recuperados y los esperables si los esqueletos estuvieran completos, corresponde a la sobrerrepresentación de restos de costillas y craneales, debido probablemente a su mayor grado de fragmentación, y la infrarrepresentación de vértebras (posiblemente por aplastamiento debido a la caída de bloques), algunos huesos del carpo y el tarso, así como de las falanges, los huesos más pequeños y periféricos del esqueleto, que pueden haberse perdido o no haber sido recuperados, al tratarse de una recogida superficial y no una excavación propiamente dicha. También es posible, sin embargo, que debido a que el espesor del hueso cortical es mucho menor que en los huesos largos, y a su tamaño, los huesos pequeños que sufrieran aplastamiento entre las rocas fueran completamente destruidos, o dejasen fragmentos demasiado pequeños para permitir la reconstrucción o incluso el reconocimiento de la parte esquelética a la que pertenecían.

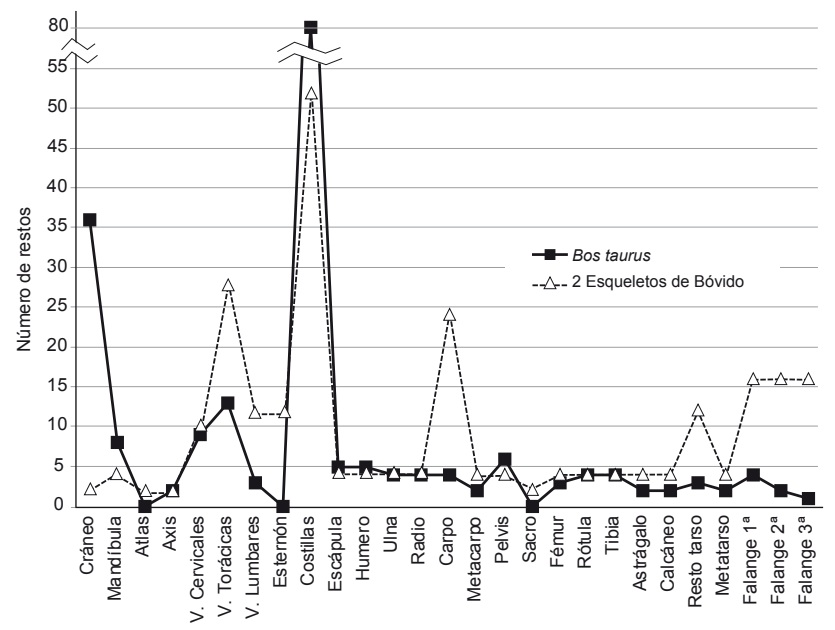

Fig. 4. Representación del número de restos hallados. Comparación con las piezas presentes en dos esqueletos de bóvido completos. 
Por lo tanto, se calculó para el conjunto de las zonas 1 y 2 un NMI de 2 para Bos taurus y 1 para ovicáprido, liebre y ciervo. En el caso de la liebre y el ovicáprido de esa zona de la cueva, sólo fue encontrado un resto óseo de cada especie.

Todos estos datos parecen indicar que los animales que se encontraron llegaron al interior de la cueva accidentalmente, lo que vendría propiciado por la difícil topografía de la cueva, de la que ya se ha hablado con anterioridad, y que podría dar lugar a que animales que buscasen refugio hubiesen quedado atrapados. Si bien es cierto que podría tratarse de una zona utilizada para deshacerse de los cadáveres de animales muertos por causas naturales $\mathrm{y}$, por tanto, descartados para el consumo, una función para la que incluso hoy en día no es demasiado extraño encontrar ejemplos en el lugar, destaca el hecho de que los restos fueran encontrados en partes de la cueva alejadas de la entrada, lo que implicaría recorrer un largo trecho desde la entrada, por terreno difícil, especialmente si no se cuenta con material de escalada y sin iluminación natural. Además, no hay que olvidar que la cueva se encuentra en una zona de gran pendiente y a unos 1025 metros de altitud sobre el nivel del mar. Todo ello sugiere más la caída accidental y deambulación de los animales en busca de una salida alternativa, que el transporte de cadáveres de animales.

\subsection{Encuadre histórico de los animales.}

A lo largo de la Historia, la talla de los animales domésticos ha ido variando en función a los intereses humanos y a las posibilidades reales de influir en ella mediante la selección para la reproducción de aquellos ejemplares que cumplieran con los criterios requeridos. Esta variación en la morfología de los animales domésticos no sólo tiene interés en los estudios de las primeras fases de la domesticación; la selección de ciertas características durante la cría de animales depende de las necesidades e intereses de los criadores (carne, leche, trabajo, compañía, etc.), lo que a su vez es un indicio de la economía y tipo de sociedad de la época. En este sentido, las variaciones en la talla de los animales domésticos con el dominio romano y posteriormente con la declinación del Imperio (Fernández Rodríguez, 2003) corresponden con los cambios en la sociedad de la época.

Pocas fuentes históricas existen sobre los acontecimientos de este periodo, siendo la principal las Crónicas de Hidacio, por lo que aún existen muchos vacíos en nuestros conocimientos de este periodo. Durante la última época del Imperio, la presión señorial y los excesivos impuestos sobre el campesinado provocaron que al principio, en las capas más bajas de la población hubiese muchos que apoyasen la llegada de los invasores germanos, aunque fuese durante poco tiempo. Sin embargo, esta paz fue de corta duración siendo frecuentes posteriormente los saqueos y conflictos con la población, aunque los grandes terratenientes parecen haber sufrido menos en este sentido que el pueblo llano (Díaz Martínez, 1983).

La cronología de los restos estudiados sitúa el conjunto faunístico en los primeros decenios de la época sueva en Galicia. La influencia de estos pueblos bárbaros de gran tradición ganadera sobre el manejo de la cabaña local, o incluso la aportación de cabezas de ganado foráneas, pudo quedar reflejada en una diferencia en las tallas medias de las especies domésticas. 
En el caso de los bóvidos de A Tara, debido a que no ha habido apenas transporte de los restos, fue posible reconstruir parte de los esqueletos de los animales, lo que permitió calcular la edad de los restos en base al análisis de sus dentaduras. Los dos bóvidos son animales con sus epífisis completamente soldadas y dentición definitiva completa, lo que nos permite suponer una edad superior a los tres años, probablemente cercana a los cinco años en base al grade de desgaste del tercer molar inferior, lo que indica que habían pasado varios años desde que habían alcanzado su tamaño definitivo y la madurez sexual.

Las medidas de todos los restos recuperados de bóvido se presentan en el Anexo. El tamaño calculado para los animales a partir de las piezas de las que se pudo obtener la longitud máxima puede verse en la Tabla 2.

\begin{tabular}{|c|c|c|c|c|c|c|}
\hline Sigla & Pieza & individuo & edad & LM (mm) & Factor & $\begin{array}{c}\text { Altura cruz } \\
(\mathbf{m m})\end{array}$ \\
\hline $\begin{array}{c}123-166-177- \\
275\end{array}$ & Metacarpo & Bos 1 & $>3$ años & 183,5 & 6,25 & 1146,88 \\
\hline 13 & Radio & Bos 1 & $>3$ años & 266,5 & 4,3 & 1145,95 \\
\hline 220 & Radio & Bos 2 & $>3$ años & 227,0 & 4,3 & 976,1 \\
\hline
\end{tabular}

Tabla 2. Cálculo de la alzada de los bóvidos encontrados. Las piezas con varios números de identificación corresponden a huesos que fueron reconstruidos tras el siglado de sus fragmentos.

Podemos comparar los datos anteriores con los encontrados por Fernández
Rodríguez (2003) para la cabaña ganadera del Noroeste Peninsular (Tabla 3 y Figura 5).

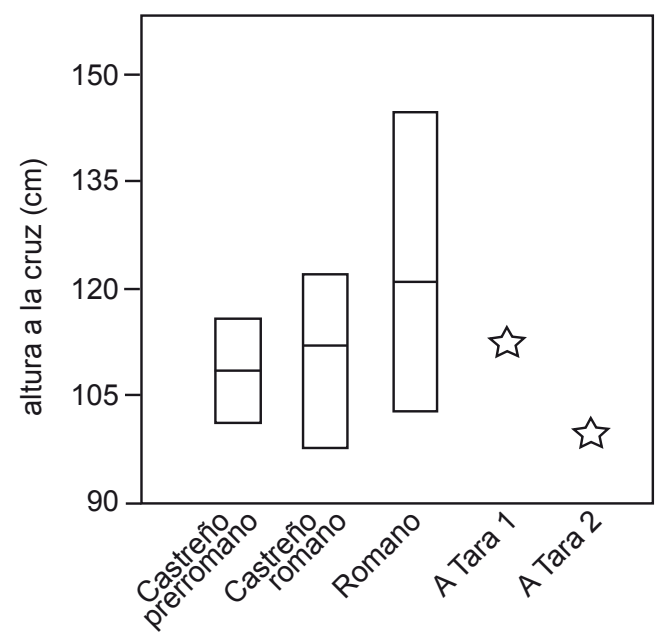

Fig. 5. Comparación de las alzadas de ganado vacuno tardohistórico del noroeste peninsular, según Fernández Rodríguez (2003), con la de los individuos de A Tara. Medidas en cm. 


\begin{tabular}{|c|c|c|c|c|c|c|}
\hline & \multicolumn{2}{|c|}{ Castreño Prerromano } & \multicolumn{2}{c|}{ Castreño Romano } & \multicolumn{2}{c|}{ Romano } \\
\hline Especie & Rango & Media & Rango & Media & Rango & Media \\
\hline Bos taurus & $101,3-115,8$ & 108,5 & $97,4-122,0$ & 112,7 & $102,6-144,6$ & 120,6 \\
\hline Ovis aries & $45,3-59,6$ & 49,8 & $47,9-62,3$ & 53,4 & $53,6-73,9$ & 62,2 \\
\hline Capra hircus & & & 64,4 & & $55,7-68,9$ & 63,4 \\
\hline
\end{tabular}

Tabla 3. Alzada de los animales domésticos del noroeste peninsular según Fernández Rodríguez (2003). Medidas en $\mathrm{cm}$.

Las dos medidas obtenidas para el individuo 1 son coincidentes e indican una alzada en la cruz de unos $114,6 \mathrm{~cm}$. La única medida para el individuo 2 da una alzada menor, de aproximadamente 97,6 $\mathrm{cm}$. Ambos están por debajo de la media de Bos taurus para la Galicia romana, estando el individuo 2 en el límite inferior de tamaño para cualquiera de las épocas.

La introducción de animales de mayor talla explicaría el aumento de la talla media en las cabañas ganaderas en Europa a 1o largo de la ocupación romana, con respecto a épocas posteriores, aunque estas mejoras no se dieron en todas las poblaciones al mismo tiempo, ni la evolución posterior fue la misma, manteniéndose o aumentando en algunos casos las tallas medias, mientras que en otras zonas las tallas disminuyeron hacia el final del Imperio Romano (Albarella et al., 2008, Armitage 1982, Teichert, 1984). En Bos taurus de Galicia la talla media y la máxima aumentó apreciablemente con la romanización, aunque no hay grandes diferencias en las tallas mínimas (Fernández Rodríguez, 2003). Teniendo esto en cuenta, no es extraño que los bovinos encontrados en Cova da Tara sean de tamaño similar a los provenientes de asentamientos castreños y romanos, o incluso a los de épocas prerromanas, a pesar de pertenecer a un periodo posterior. También es posible que no todas las poblaciones domésticas fueran sometidas a los mismos esfuerzos de mejora. Si tenemos en cuenta que a pesar del aumento de la media y las tallas máximas, las tallas mínimas no aumentaron, esto podría deberse a que aunque se introdujeron animales de mayor talla, la cabaña ganadera local, de menor tamaño, no tuvo necesariamente que ser sustituida por completo durante la romanización, o todas las poblaciones sometidas a cruces. Incluso es posible que en algunas zonas los animales importados tuviesen dificultades para adaptarse al clima y las condiciones de vida, por lo que en ciertas condiciones los animales locales podrían haber presentado menores exigencias en cuanto a su alimentación y cuidados, y haber sido preferidos por sus facilidades de mantenimiento. Sin embargo, datos de yacimientos de la Alta Edad Media del País Vasco (Grau Sologestoa, 2009; Escribano Sanz, 2000) indican que, al menos en esas poblaciones, las tallas de los animales domésticos disminuyeron tras el fin del Imperio.

Los dos ejemplares de Bos taurus recuperados son de edad relativamente 
avanzada, habiendo ya sobrepasado la edad a la que se alcanza el crecimiento máximo. Hubiese sido más económico su sacrificio si su único interés fuera la carne. El que los animales siguieran vivos puede suponer que se trataba de animales destinados a la reproducción y cría o que también eran explotados de otras maneras, como la obtención de leche o la ayuda con el trabajo agrícola.

A pesar de que en los últimos siglos se han introducido muchas mejoras en la cría y selección de animales, alcanzando la mayoría de razas de animales domésticos tamaños muy superiores a los de las poblaciones durante el dominio romano, existen hoy en día en Galicia varias razas animales de tamaño relativamente pequeño, con valores de altura a la cruz próximos a los encontrados en animales de épocas prerromanas. En concreto, en cuanto a ganado vacuno destaca la vaca Cachena, que sobrevive aún hoy en día y es objeto de protección especial. Tiene una alzada de entre 100 y $130 \mathrm{~cm}$ para las hembras, y de entre 105 y $135 \mathrm{~cm}$ para los machos (Xunta de Galicia, 2000). Es una raza adaptada a zonas montañosas, y tradicionalmente explotada en régimen extensivo o semiextensivo, lo que podría explicar su pequeño tamaño, ya que al tener que explotar zonas más agrestes no pueden desarrollar un gran tamaño. La vaca Cachena es originaria de las regiones montañosas de Ourense; sin embargo a finales de los noventa su explotación se extendió a toda Galicia.

\subsection{Aproximación a la dieta de los bóvidos de A Tara.}

Las clasificaciones de dieta de una especie no son, en muchos casos, algo absoluto, y la dieta de una población concreta no sólo depende de qué tipo de alimentos sean los más adecuados, sino también de cuales tienen a su disposición. Así podemos encontrar poblaciones de especies generalmente clasificadas como ramoneadoras que adoptan una alimentación mixta o pastadora, o al contrario. La dentición de Bos taurus encontrada posee unas características de mesodesgaste que se encuentra en animales ramoneadores o de dieta mixta, pero es menos frecuente en los pastadores, aunque sí aparece en pastadores que recurren a vegetales con menor cantidad de fitolitos. Las cúspides de los molares superiores son altas y redondeadas o afiladas, como se muestra en la Figura 6, en lugar de romas y bajas, lo que indica una dieta con un bajo grado de abrasión (Fortelius y Solunias, 2000). Haynes (1984) encontró que las poblaciones de bisontes del Wood Buffalo National Park tenían un menor ritmo de desgaste en el primer molar mandibular, así como cúspides más altas y afiladas que aquellas de los bisontes de las llanuras, lo que atribuyó a que la dieta de los primeros estaba basada en plantas ciperáceas abundantes en aquella zona, con mucha menor cantidad de fitolitos que la hierba de las llanuras. 

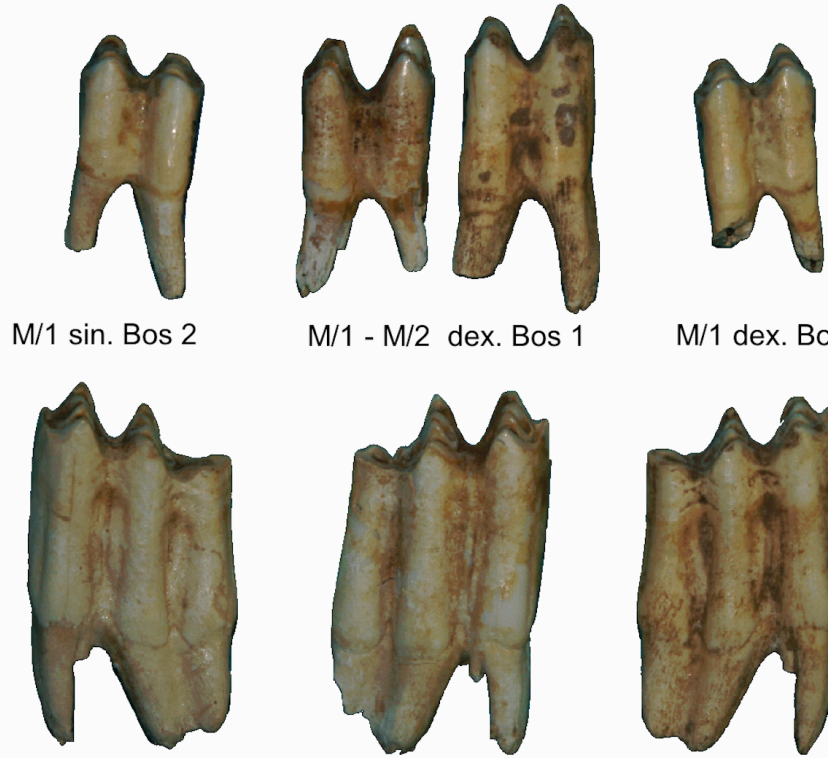

$\mathrm{M} / 1-\mathrm{M} / 2$ dex. Bos 1

$\mathrm{M} / 1$ dex. Bos 2

$M / 3 \sin$. Bos 1

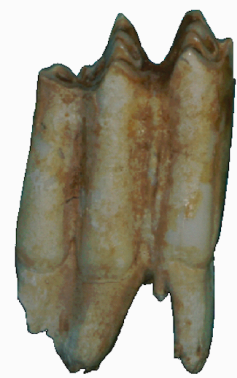

M/3 dex. Bos 1

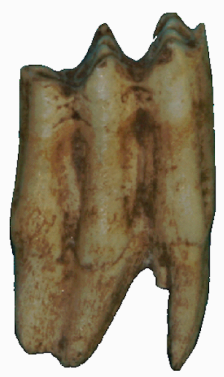

$\mathrm{M} / 3$ dex. Bos 2
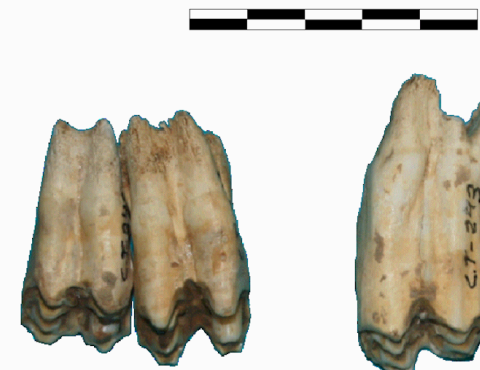

$\mathrm{M} 1 /-\mathrm{M} 2 / \sin$. Bos 2

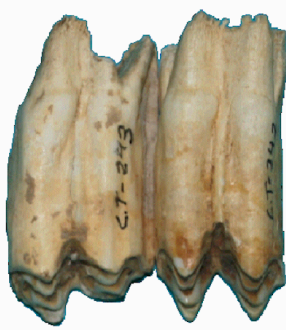

M3/ - M2/ dex. Bos 2

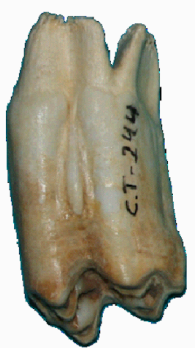

M3/ dex. Bos 1

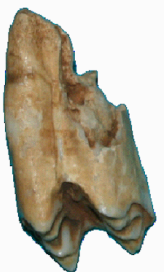

M1/ dex. Bos 1

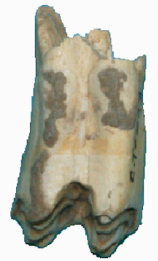

$\mathrm{M} 1 / \sin$. Bos 1

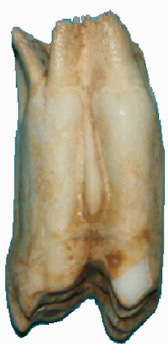

$M 3 / \sin$. Bos 1

Fig. 6. Molares de bovino de A Tara, mostrando un grado escaso de mesodesgaste. Escala en $\mathrm{cm}$. 
Al haberse recuperado únicamente dos animales, no es posible realizar un análisis estadístico de la población. A pesar de eso, su perfil dental podría considerarse un indicio de que estos animales tenían un porcentaje importante en su dieta de alimentos poco abrasivos, como podrían ser hojas, helechos, hierbas jóvenes o arbustos, lo que concuerda con el tipo de alimentación que podrían tener animales no estabulados que pastasen libremente durante la mayor parte del día.

Los análisis de isótopos estables son una herramienta usada con frecuencia en una gran variedad de campos, como pueden ser fisiología, ecología, o paleontología, y cada vez más los análisis de isótopos estables de $\mathrm{C}$ y $\mathrm{N}$ en colágeno óseo se utilizan en arqueología para ampliar el espectro de información que los restos humanos y animales pueden proporcionar, Los valores de $\delta^{15} \mathrm{~N}$ y $\delta^{13} \mathrm{C}$ están relacionados con el tipo de dieta y hábitat, por lo que permiten conocer mejor la forma de vida de las comunidades analizadas (De Niro y Epstein, 1978, 1981; Bocherens y Fogel, 1995).

Los resultados isotópicos $\left(\delta^{13} \mathrm{C}\right.$ y $\left.\delta^{15} \mathrm{~N}\right)$ de las muestras figuran en la tabla 4. Los criterios de calidad para el colágeno extraído se cumplen sobradamente en todos los casos, ya que los porcentajes de nitrógeno y carbono son similares a los del colágeno óseo fresco, al igual que la relación entre el carbono y el nitrógeno $(\mathrm{C} / \mathrm{N})$, comprendida entre 2,9 y 3,6, como en el colágeno actual (Grandal et al., 2010).

\begin{tabular}{|l|l|l|l|l|l|}
\hline Muestra & \% N & Delta $^{{ }^{\mathbf{5}} \mathbf{N}}$ & $\mathbf{\%} \mathbf{C}$ & Delta $^{\mathbf{1 3}} \mathbf{C}$ & $\mathbf{C} / \mathbf{N}$ \\
\hline $\mathbf{5 0 0}$ & 15,2 & 3,2 & 39,8 & $-21,5$ & 3,1 \\
\hline $\mathbf{5 0 1}$ & 14,7 & 3,3 & 39,3 & $-21,9$ & 3,1 \\
\hline $\mathbf{5 0 2}$ & 14,3 & 3,4 & 37,8 & $-21,9$ & 3,1 \\
\hline $\mathbf{5 0 4}$ & 15,2 & 3,8 & 40,7 & $-21,8$ & 3,1 \\
\hline $\mathbf{5 0 5}$ & 15,0 & 3,4 & 40,2 & $-21,6$ & 3,1 \\
\hline $\mathbf{5 0 6}$ & 14,7 & 3,7 & 38,6 & $-21,7$ & 3,1 \\
\hline $\mathbf{5 0 7}$ & 15,5 & 3,8 & 42,1 & $-21,9$ & 3,2 \\
\hline $\mathbf{5 0 8}$ & 13,5 & 3,5 & 36,4 & $-21,9$ & 3,1 \\
\hline $\mathbf{5 0 9}$ & 15,3 & 3,7 & 41,5 & $-22,1$ & 3,2 \\
\hline
\end{tabular}

Tabla 4. Resultados del análisis isotópico de los restos de Bos taurus de A Tara. \% de $\mathrm{C}$ y $\mathrm{N}$ expresan el porcentaje de estos elementos en el colágeno óseo. Los valores de delta se expresan en \%o. $\mathrm{C} / \mathrm{N}$ es la relación atómica entre ambos elementos en el colágeno analizado.

Los valores de $\delta^{13} \mathrm{C}$ obtenidos a partir de las muestras de bóvidos de a Tara se encuentran entre $21,4 \%$ y $22,1 \%$. Coinciden por tanto con los que se obtendrían de una dieta a partir de plantas C3, árboles y herbáceas de climas templados y fríos (con valores medios de $-26,5 \pm 2 \%$, que se traducirían en el colágeno óseo de herbívoros en aproximadamente $-21,5 \%$ debido al fraccionamiento isotópico que se produce durante su asimilación). Puede descartarse la contribución a la dieta de plantas C4, herbáceas de climas tropicales como el maíz, la caña de azúcar o el mijo, con valores de 813C netamente más positivos (media de -12,5 $\pm 1 \%$ ). El mijo es un cereal que aparece en el norte de la Península Ibérica en la transición del Bronce final a la Primera la Edad del Hierro (Vázquez Varela, 1993) pero su cultivo no fue frecuente en la Galicia romana 
(Suárez Piñeiro, 2004) y aparece escasamente en los espectros polínicos gallegos de época castreña (Dopazo et al., 1996). Apenas existen datos sobre la intensidad de su cultivo en la época que nos ocupa.

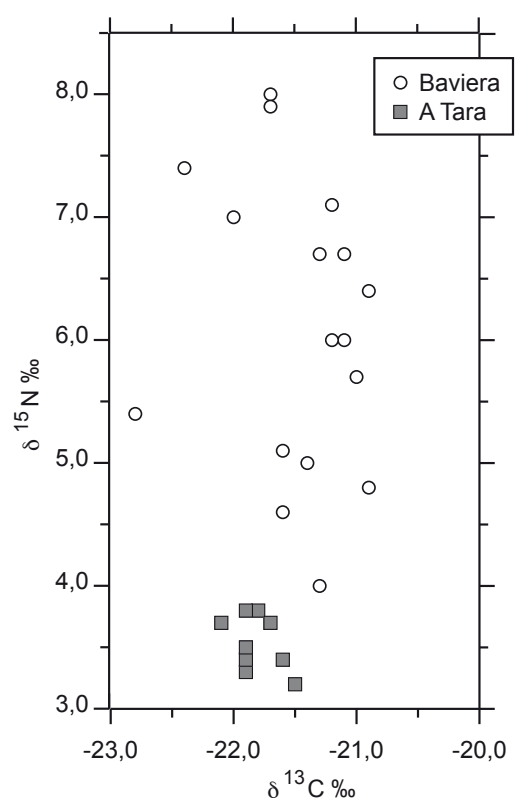

El $\delta^{15} \mathrm{~N}$ de las muestras varia entre $3,3 \%$ y $3,8 \%$, valores que, si los comparamos con los valores de Bos taurus tardorromano y altomedieval de Alemania (Hakenbeck et al., 2010) se sitúan muy por debajo de la media (fig. 7).
Fig. 7. Comparación de valores isotópicos de los bóvidos de A Tara con individuos centroeuropeos (Hakenbeck et al., 2010) de cronología aproximadamente similar.
Hay varias posibles explicaciones para estos valores. Estudios sobre materiales actuales demuestran que los valores de $\delta^{15} \mathrm{~N}$ en suelos y plantas muestran un gradiente latitudinal y altitudinal que responde a las variaciones en el clima, debido al descenso de la actividad microbiana en los suelos de las zonas frías (Mariotti et al., 1980; Amundson et al., 2003). En hábitats alpinos, el $\delta^{15} \mathrm{~N}$ de ungulados modernos desciende un $1,1 \%$ por cada 1000 metros de elevación sobre el nivel del mar (Mannel et al., 2007). Las altitudes medias en la zona de A Tara, calculadas en un radio de unos $10 \mathrm{~km}$, superan los $900 \mathrm{~m}$ sobre el nivel del mar. Si los bóvidos se mantuvieron preferentemente en las zonas altas de la sierra, los valores isotópicos de las plantas de las que se alimentaban pueden haber sido apreciablemente bajos. Existe también un gradiente Norte-Sur para los valores isotópicos del $\mathrm{N}$ en los suelos y las plantas causado igualmente por la disminución de la actividad microbiana en climas fríos. Por ello, sería de esperar que los individuos de las poblaciones norteñas presentasen valores de $\delta^{15} \mathrm{~N}$ también bajos. Es probable que el gradiente latitudinal tenga una menor incidencia sobre los valores de partida de la dieta que la altitud de la zona, que en el caso de los individuos con los que se han comparado, es más baja (apenas alcanza 
los $500 \mathrm{~m}$ sobre el nivel del mar en Baviera). Por último, el conjunto de ganado vacuno de Baviera procede de un contexto muy antropizado. Si los animales se alimentaron en zonas de pastos preparados al efecto, es posible que el suelo estuviera sometido a manejo y enriquecido con abonos orgánicos, lo que eleva considerablemente los valores isotópicos del nitrógeno en las plantas y a lo largo de toda la cadena trófica (Van Klinken et al., 2000).

Por otra parte, las plantas fijadoras de $\mathrm{N}$, como las leguminosas, presentan valores especialmente bajos en su $\delta^{15} \mathrm{~N}$ ya que lo obtienen directamente del aire a través de micorrizas simbiontes (Hobbie et al., 2000). Ericáceas, leguminosas y rosáceas son familias especialmente destacables en las zonas de matorral de O Courel. Existen 65 especies de leguminosas en esa región, siendo abundantes en las zonas altas de la sierra en formas arbustivas: retama (Cytisus scoparius), carquesa (Pterospartum tridentatum), codeso (Adenocarpus complicatus) o incluso el tojo (Ulex sp. y Genista sp.), que a pesar de sus espinas, es consumido por las vacas cuando sus brotes aún están tiernos, se emplea como forraje y constituye una parte importante de las zonas de matorral. Sus formaciones dominan el paisaje de ciertas áreas, y son preferibles como zonas de pastoreo a los brezales, formaciones de Calluna y Erica, ya que la presencia de taninos y la baja digestibilidad en estas especies las hacen poco adecuadas para la alimentación de ovejas y vacas (González Hernández y Silva Pando, 1999; González Hernández et al., 2003).

Si tenemos en cuenta que su dentición parece indicar un tipo de dieta poco abrasiva, es posible que estos valores representen un cierto aporte de plantas fijadoras de $\mathrm{N}$
(Virginia y Delwiche, 1982), tales como podrían ser la paja de leguminosas usada como forraje, el trébol en praderas o tojo y retama en las zonas de matorral. Incluso hoy en día se sigue manteniendo en algunas zonas el uso de las zonas de matorral como zonas de pasto para ganado, abundando los tojos y retama, fijadoras de nitrógeno y que son además empleadas como cama para el ganado (Xunta de Galicia 2005).

Hay que recordar que la zona de alta montaña gallega tiene unas características climáticas, geomorfológicas y de vegetación distintas de otras zonas de la Península Ibérica o incluso de las zonas bajas de Galicia, lo que influenciaría el modo de aprovechamiento local del territorio, Hoy en día en el Courel, dentro de las tierras de uso agrario, el principal uso es la ganadería. El espacio destinado a los forrajes, especialmente los forrajes verdes, incluyendo praderas, supera a cualquier otro tipo de cultivo (Xunta de Galicia, 2005).

La evolución de la vegetación en la zona durante el Holoceno es bien conocida gracias a los estudios polínicos realizados en la cercana laguna de Lucenza (ver Fig. 1). Las secuencias polínicas de la laguna de Lucenza muestran una disminución del polen arbóreo durante el periodo Atlántico (desde 2500 años BP hasta la actualidad) ligada a un incremento plantas herbáceas. Esta deforestación va unida también a una abundancia de microcarbones, lo que permite suponer una importante acción antrópica para aclarar la vegetación por medio de rozas. Este tipo de actividad frecuentemente se ha asociado con la expansión de la agricultura, pero también va ligada a la obtención de pastos para la ganadería (Ramil Rego, 1993a). Este podría ser el caso de $\mathrm{O}$ Courel ya que aquí no se 
detecta la presencia de polen de cereales en el espectro polínico hasta aproximadamente 1500 años BP y con una representación muy escasa, inferior al 3\% que se considera indicativo de actividades agrícolas en las inmediaciones (López Sáez, et al., 2003). Otras secuencias provenientes de cotas más bajas de la geografía gallega muestran ya la presencia de cultivos de cereales, especialmente el trigo, desde varios milenios antes (Santos Fidalgo et al., 1997, 2000; Ramil Rego, 1993b). En ningún caso los espectros polínicos de montaña en Galicia reflejan el cultivo de cereales a cotas altas (Ramil Rego, 1993a). Pero el espectro polínico tampoco señala la presencia importante de pastizales, ya que las especies marcadoras de pradera (López Sáez et al., 2003) también están muy escasamente representadas en los niveles superiores de Lucenza (Santos et al., 2000).

Mientras que las zonas más altas pudieron presentar dificultades para su uso como tierras de labor o praderío, eso no excluye un aprovechamiento de otros recursos, como la madera, las castañas o zona de alimentación de ganado.

Las zonas montañosas gallegas se han usado y aún lo hacen como zonas de pastoreo extensivo, con la presencia de rebaños mixtos en los que el ganado bovino comparte el espacio con ovejas y cabras, aprovechándose las distintas características de los animales para hacer un aprovechamiento más eficiente de los recursos de una misma área en montes gestionados de forma comunal.

La presencia de estos bóvidos en la cueva parece señalar que el uso de las tierras circundantes para ganadería extensiva también se realizó durante la época sueva, mientras que las características dentales y los valores isotópicos de colágeno sugieren su pastoreo en zonas de matorral o en praderas abiertas con abundancia de trébol. Aunque la primera opción concuerda mejor con el entorno en el que fueron encontradas, no se puede descartar que tuviesen distintas zonas de pastoreo dependiendo de la época.

\section{CONCLUSIONES.}

Las características de la Cova da Tara hacen que haya sido a veces una trampa natural, habiendo caído en su interior tanto animales domésticos como salvajes. La gran pendiente existente en el interior impediría la salida de los animales por su propio pie y haría muy difícil rescatar a los animales atrapados. Esto hace que la cueva ofrezca en su interior una muestra de la fauna que frecuentaba la zona, incluyendo los animales domésticos. Este tipo de yacimiento puede ser de gran interés a la hora de complementar la información obtenida a partir de los restos animales encontrados en asentamientos humanos, especialmente en zonas como Galicia, en las que los restos óseos se degradan con rapidez debido a las características geológicas de la mayor parte del territorio.

Si bien durante la época romana se introdujeron animales de mayor tamaño, las tallas mínimas no variaron, y no parece haber una tendencia al aumento de las tallas de los animales domésticos durante la Alta Edad Media. Durante la época sueva los campesinos vivieron una difícil situación social, debido a los conflictos con los suevos y la presión de los impuestos, lo que podría haber impulsado a que intentasen maximizar el provecho obtenido de los recursos de los que ya disponían, teniendo poca capacidad para invertir en mejoras o arriesgarse con variedades ganaderas más delicadas cuando 
las pérdidas, en caso de su muerte, serían difíciles de asumir. Incluso hoy en día varias de las razas de animales domésticos gallegos propios de zonas montañosas tienen un tamaño similar a los que se podrían encontrar en la época romana y prerromana, a pesar de que la mayoría de las razas de la península alcancen tamaños mucho mayores. Esto permite suponer que frente a un aumento de talla, a lo largo del tiempo, en ciertas zonas se prefirió seleccionar preferentemente otras características, como la capacidad de trabajo del ganado vacuno, la resistencia a condiciones climáticas duras o la capacidad de subsistir en zonas subóptimas, características que permitirían dedicar menos tiempo y recursos al cuidado de los animales y permitirían compaginar mejor la ganadería con otras actividades. Así, no siempre debe asumirse que un mayor tamaño de los animales por sí solo resultaría más provechoso para sus cuidadores en cualquier circunstancia.

Las características dentales y los valores isotópicos en colágeno óseo indican que los Bos taurus de A Tara aprovecharían como pasto las áreas de matorral de las zonas altas, dando uso a un espacio que de otra manera proporcionaría un provecho mucho más limitado a los pobladores de la zona, y que permitiría el mantenimiento de los animales sin tener que sacrificar tierras adecuadas para el cultivo.

Los bóvidos recuperados en el interior demuestran la explotación de los animales en régimen extensivo o semiextensivo, pudiendo recorrer libres la zona, al menos durante las horas diurnas, para aprovechar la vegetación presente. Cabe suponer que esto se debería a que los pobladores no tenían acceso a pastos de mayor calidad para sus ganados, o bien el esfuerzo necesario para realizar el desplazamiento hasta ellos no sería compensado por las ventajas que supondría. Ya que no conocemos hasta que punto los dueños de los animales dependían de ellos, o si tan sólo eran un recurso adicional, dependiendo sus ingresos y manutención principales de otras fuentes, no podemos saber con seguridad hasta que punto era para ellos importante proporcionarles cuidados de calidad. El hecho de que ambos animales sobrepasaran los tres años de edad, hace que podamos suponer que no se destinaban al consumo, por lo que se trataría de animales de cría o para proporcionar otros recursos, como productos lácteos o fuerza de trabajo.

\section{AGRADECIMIENTOS}

Este trabajo hubiese sido imposible sin la ayuda prestada por los espeleólogos que colaboraron durante el recorrido y los trabajos en las cuevas, y proporcionaron tanto las fotografías del interior como la topografía subterránea. Aunque son muchos los que colaboraron, nuestro agradecimiento especial por las incontables horas de trabajo es para Victorino Marzabal (Tarín), Begoña Barreiro Ben, Reinaldo Costas Vázquez y Rosa María Suárez Pérez. Este trabajo se encuadra en el Programa de Consolidación e Estructuración Redes (R2014/024) de la Xunta de Galicia.

\section{BIBLIOGRAFÍA}

Albarella, U., Johnstone, C. y Vickers, K. 2008. The development of animal husbandry from the Late Iron Age to the end of the Roman period: a case study from South-East Britain. Journal of Archaeological Science 35, 1828-1848. 
Altuna, J. 1980. Historia de la domesticación animal en el País Vasco desde sus orígenes hasta la romanización. Munibe 32, 1-164.

Armitage, P. L. 1982. Developments in British cattle husbandry from the Romano-British period to early modern times. The Ark 9, 50-54.

Bocherens, H. y Fogel, M. L. 1995. Trophic Structure and Climatic Information From Isotopic Signatures in Pleistocene Cave Fauna of Southern England. Journal of Archaeological Science 22, 327-340.

Bocherens, H., Billiou, D., Patou-Mathis, M., Bonjean, D., Otte, M. y Mariotti, A. 1997. Palaeobiological implications of the isotopic signatures $(13 \mathrm{C}, 15 \mathrm{~N})$ of fossil mammal collagen in Scladina Cave (Sclayn, Belgium). Quaternary Research 48, 370-380.

De Niro, M. J. y Epstein, S. 1978. Influence of diet on the distribution of carbon isotopes in animals. Geochimica et Cosmochimica Acta 42, 495-506.

De Niro, M. J., Epstein, S. 1981. Influence of diet on the distribution of nitrogen isotopes in animals. Geochimica et Cosmochimica Acta 45, 341-351.

Díaz Martínez, P. de la C. 1983. Los distintos "grupos sociales" del noroeste hispano y la invasión de los suevos. Studia historica. Historia Antigua 1, 75-88.

Dopazo Martínez, A., Fernández Rodríguez, C. y Ramil Rego, P. 1996. Arqueometría aplicada a yacimientos galaico-romanos del NW peninsular: valoración de la actividad agrícola y ganadera. P. Ramil Rego, C. Fernández Rodríguez y M. Rodríguez Guitián (coords.), Biogeografía Pleistocena-Holocena de la Península Ibérica, Xunta de Galicia, Santiago de Compostela, 317-331.
Escribano Sanz, O. 2000. La dieta animal de época romana en Álava. Zainak. Cuadernos de Antropología-Etnografía 20, 203-210.

Fairbanks, R. G., Mortlock, R. A., Chiu, T-C. Cao, L., Kaplan, A., Guilderson, T. P., Fairbanks, T. W. y Bloom, A. L. 2005. Marine Radiocarbon Calibration Curve Spanning 0 to 50,000 Years B,P, Based on Paired ${ }^{230} \mathrm{Th} /{ }^{234} \mathrm{U} /{ }^{238} \mathrm{U}$ and ${ }^{14} \mathrm{C}$ Dates on Pristine Corals. Quaternary Science Reviews 24, 1781-1796.

Fernández Rodríguez, C. 2003: Ganadería, Caza y Animales de Compañía en la Galicia Romana: Estudio Arqueozoológico, Brigantium: Boletin do Museo Arqueolóxico e Histórico da Coruña 15, A Coruña.

García-Vázquez, A., Vidal-Gorosquieta, A. y Grandal-d'Anglade, A. 2011. El clima holoceno a través de las paleodietas del oso pardo (Ursus arctos) y el Uro (Bos primigenius). A. Pérez-García, F. Gascó, J.M. Gasulla y E. Escaso (eds.), Viajando a Mundos Pretéritos, Ajuntament de Morella, Morella, 131-143,

García-Vázquez, A., Grandal-d'Anglade, A., Vaqueiro-Rodríguez, M. y VidalRomaní, J.R. 2011. On the relation between cave and brown bears in $\mathrm{O}$ Courel Sierra (Galicia, NW Spain). Quaternaire 4, 59-69.

González-Hernández, M. P. y Silva-Pando, F. J. 1999. Nutritional attributes of understory plants known as components of deer diets. Journal of Range Management 52, 132-138.

González-Hernández, M. P., Karchesy, J. y Starkey, E. E. 2003. Research observation: Hydrolyzable and condensed tannins in plants of northwest Spain forests. Journal of Range Management 56, 461-465. 
Grandal-d'Anglade, A., López-González, F. y Vidal-Romaní, J. R. 1997. Condicionantes en la distribución de macromamíferos en Galicia (NW Península Ibérica) durante el Cuaternario superior. Cadernos do Laboratorio Xeolóxico de Laxe 22, 43-66.

Grandal-d'Anglade, A., Pérez-Rama, M., García-Vázquez, A., Vidal-Gorosquieta, A. y González-Fortes, G. 2010: Geocaracterización de yacimientos arqueológicos: conservación de restos paleontológicos y obtención de datos biogeoquímicos, A.J. López Díaz y E. Ramil Rego (eds.), Arqueoloxía: Ciencia e Restauración, Monografías do Museo de Prehistoria e Arqueoloxía de Vilalba 4, Vilalba, 57-70.

Grau Solagestoa, I. 2009. Ganadería en la Alta Edad Media, Estudio comparativo de los yacimientos alaveses de Zornoztegi, Zaballa y SalvatierraAgurain. Munibe 60, 253-280.

Grigson, C. 1982. Sex and age determination in some bones and teeth of domestic cattle: a review of the literature" B. Wilson, C. Grigson y S. Payne (eds.) Ageing and Sexing Animal Bones from Archaeological Sites, BAR British Series 109, Oxford, 7-23.

Hakenbeck, S., Mcmanus, E. Geisler, H. Grupe, G. y O'Connell, T. 2010. Diet and Mobility in Early Medieval Bavaria: A Study of Carbon and Nitrogen Stable Isotopes. American Journal of Physical Anthropology 143, 235-249.

Haynes, G. 1984. Tooth wear rate in northern bison. Journal of Mammalogy 85, 487-491.

Hobbie, E. A., Macko, S. A. y Williams, M. 2000. Correlations between foliar $\mathrm{d} 15 \mathrm{~N}$ and nitrogen concentrations may indicate plant-mycorrhizal interactions. Oecologia 122, 273-283.
López Sáez, J.A.; López García, P. y Burjachs, F. 2003. Arqueopalinología: Síntesis Crítica. Polen 12, 5-35.

Luzón Nogué, J.M. y Sánchez-Palencia Ramos, F. J. 1980: El Caurel, Excavaciones Arqueológicas en España 110, Madrid.

Lynch, A.H., Hamilton, J. y Hedges, R. E. M. 2008. Where the wild things are: aurochs and cattle in England. Antiquity 82, 1025-1039.

Mariotti, A., Pierre, D., Vedy, J.C. y Bruckert, S. 1980. The abundance of natural nitrogen 15 in organic matter of soils along an altitudinal gradient. Catena 7, 293-300.

Noe-Nygaard, N., Price, T.D. y Hede, S.U. 2005. Diet of aurochs and early cattle in southern Scandinavia: evidence from $15 \mathrm{~N}$ and $13 \mathrm{C}$ stable isotopes. Journal of Archaeological Science 32, 855-871.

Prummel, W. y Frisch, H. J. 1986. A guide for the distinction of species, sex and body side in bones of sheep and goat. Journal of Archaeological Science 13, 567-577.

Ramil Rego, P. 1993a. Evolución climática e historia de la vegetación durante el Pleistoceno Superior y Holoceno enlas regiones montañosas del $\mathrm{NW}$ ibérico. A. Pérez Alberti, L. Guitián Rivera y P. Ramil Rego (Eds), La evolución del paisaje en las montañas del entorno de los Caminos Jacobeos, Xunta de Galicia, Santiago de Compostela, 25-60.

Ramil Rego, P. 1993b. Paleoetnobotánica de yacimientos arqueológicos holocenos de Galicia, (N,O, Cantábrico). Munibe 45, 165-174.

Santos Fidalgo, L., Vidal Romaní, J.R. y Jalut, G. 1997. Contribución al conocimiento de la vegetación holocena 
en el NO de la Península Ibérica (Galicia, España). Cadernos do Laboratorio Xeolóxico de Laxe 22, 99-119.

Santos Fidalgo, L., Vidal Romaní, J.R. y Jalut, G. 2000. History of vegetation during the Holocene in the Courel and Queixa Sierras, Galicia, northwest Iberian Peninsula. Journal of Quaternary Science 15, 621-632.

Suárez Piñeiro, A.M. 2004. Sentados á mesa dun galaico-romano: dieta, alimentación e hábitos culinarios na Galicia romana. Gallaecia 23, 155-172.

Teichert, M. 1984: Size variation in cattle from Germania romana and Germania libera. C. Grigson y J. Clutton-Brock (eds,), Animals in Archaeology: 4, Husbandry in Europe, BAR International Series 107, Oxford, 93-103,

Van Klinken, G.J.; Richards, M.P. y Hedges, R.E.M. 2000. An overview of causes for stable isotopic variations in past European human populations: environmental, ecophysiological and cultural effects. In: S.H. Ambrose, M.A. Katzenberg (Eds.), Biogeochemical Approaches to Palaeodietary Analysis, Kluwer Academic/Plenum Publishers, New York, pp. 39-63.

Vaqueiro, M. 2007. Topografía Subterránea. Láminas Karst y Pseudokarst de Galicia y Portugal. 2004-2007. Depósito legal VG:172-07.

Vázquez Varela, J.M. 1993-1994. El cultivo del mijo, (Panicum miliaceum, L.) en la cultura castreña del Noroeste de la Península Ibérica. Cuadernos de Estudios Gallegos XLI (106), 65-73.

Vidal Romaní, J. R. Grandal d'Anglade, A., Fernández Ferrín, J. y Vila Anca, R. 1992. El Glaciocarst del Courel (Lugo). Furada 6, 35-40.

Virginia, R. A. y Delwiche, C. C. 1982. Natural $15 \mathrm{~N}$ abundance of presumed N2-fixing and non-N2-fixing plants from selected ecosystems. Oecología 54, 317325.

Xunta De Galicia 2000: $O R D E$ do 27 de setembro de 2000 pola que se aproba a regulamentación específica do Libro Xenealóxico da Raza Bovina Cachena, Diario Oficial de Galicia, no 207 de 25 de octubre, 14.494 - 14.498.

Xunta De Galicia 2005: Plan de ordenación de los recursos naturales, Espacio natural protegido Os Ancares - O Courel, Tomo 1, Xunta de Galicia, Consellería de Medio Ambiente, Dirección Xeral de Conservación da Natureza.

Xunta De Galicia 2011: DECRETO 149/2011, de 7 de julio, por el que se establece el Catálogo oficial de razas ganaderas autóctonas de Galicia, se regula el reconocimiento oficial de las asociaciones de criadores de razas autóctonas de Galicia que creen o gestionen libros genealógicos $y$ se aprueban los programas para su conservación, mejora y fomento, Diario Oficial de Galicia 141, 22 julio del 2011, 20634-20714. 
ANEXO. TABLAS DE MEDIDAS DE BOS TAURUS DE A TARA.

Abreviaturas:

CR: craneal

MA: mandibular

art: articulación

s art: superficie articular

L: longitud

A: anchura

Al: altura
D: diámetro

T: transversal

AT: anteroposterior

M: máximo

m: mínimo

$\mathrm{p}$ : proximal

d: distal

\begin{tabular}{|c|c|c|c|c|c|c|c|c|c|c|c|}
\hline & & & & & L serie & L serie & $\begin{array}{l}\text { L rama } \\
\text { horizon- } \\
\text { tal hasta }\end{array}$ & Al & & & $\begin{array}{c}\text { Al } \\
\text { mediana }\end{array}$ \\
\hline Número & pieza & lado & $\begin{array}{l}\text { main- } \\
\text { duo }\end{array}$ & $\begin{array}{l}\text { L serie } \\
\text { molar }\end{array}$ & $\begin{array}{l}\text { premo- } \\
\text { lar }\end{array}$ & $\begin{array}{l}\text { molari- } \\
\text { formes }\end{array}$ & $\begin{array}{c}\text { borde } \\
\text { oral } \\
\text { alveolo } \\
\text { P2 }\end{array}$ & $\begin{array}{l}\text { tras } \\
\text { M3 }\end{array}$ & M1 & $\begin{array}{l}\text { A1 irente } \\
\text { P2 }\end{array}$ & $\begin{array}{l}\text { mediana } \\
\text { rama } \\
\text { vertical }\end{array}$ \\
\hline $107-165$ & $\begin{array}{l}\text { Man- } \\
\text { díbula }\end{array}$ & $\mathrm{S}$ & Bos 1 & 78,69 & 45,02 & 124,04 & 239 & 67,92 & 48,94 & 41,52 & 143,59 \\
\hline
\end{tabular}

\begin{tabular}{|c|c|c|c|c|c|}
\hline Número & pieza & lado & Individuo & LM & AM \\
\hline 247 & Incisivo & $\mathrm{S}$ & Bos 2 & 12,07 & 7,97 \\
\hline 248 & Incisivo & $\mathrm{D}$ & Bos 2 & 12,32 & 7,99 \\
\hline 249 & Incisivo & $\mathrm{S}$ & Bos 2 & 11,91 & 7,34 \\
\hline 261 & Premolar $2_{\mathrm{CR}}$ & $\mathrm{S}$ & Bos 1 & 13,97 & 12,13 \\
\hline 256 & Premolar $3_{\mathrm{CR}}$ & D & Bos 1 & 16,14 & 14,60 \\
\hline 257 & Premolar $3_{\mathrm{CR}}$ & S & Bos 1 & 16,15 & 14,46 \\
\hline 258 & Premolar $4_{\mathrm{CR}}$ & D & Bos 1 & 16,43 & 19,02 \\
\hline 259 & Premolar $4_{\mathrm{CR}}$ & S & Bos 1 & 16,70 & 18,18 \\
\hline 290 & Premolar $4_{\mathrm{CR}}$ & D & Bos 2 & 15,86 & 18,60 \\
\hline 245 & Molar $1_{\mathrm{CR}}$ & D & Bos 1 & 23,62 & 20,97 \\
\hline 239 & Molar $1_{\mathrm{CR}}$ & $\mathrm{S}$ & Bos 1 & 24,07 & 21,54 \\
\hline 241 & Molar $1_{\mathrm{CR}}$ & $\mathrm{S}$ & Bos 2 & 20,87 & 19,71 \\
\hline 242 & Molar $2_{C R}$ & $\mathrm{D}$ & Bos 1 & 23,86 & 23,16 \\
\hline 238 & Molar $2_{\mathrm{CR}}$ & $\mathrm{S}$ & Bos 1 & 24,07 & 23,48 \\
\hline 240 & Molar $2_{\mathrm{CR}}$ & $\mathrm{S}$ & Bos 2 & 21,63 & 22,23 \\
\hline 244 & Molar $3_{\mathrm{CR}}$ & D & Bos 1 & 27,65 & 22,47 \\
\hline 243 & Molar $3_{\mathrm{CR}}$ & D & Bos 2 & 27,15 & 21,18 \\
\hline 237 & Molar $3_{\mathrm{CR}}$ & $\mathrm{S}$ & Bos 1 & 27,55 & 22,26 \\
\hline 246 & Premolar $2_{\mathrm{MA}}$ & D & Bos 2 & 10,87 & 7,78 \\
\hline 260 & Premolar 3 MA & D & Bos 2 & 18,18 & 11,50 \\
\hline 262 & Molar $1_{\mathrm{MA}}$ & D & Bos 1 & 23,39 & 15,82 \\
\hline 264 & Molar $1_{\mathrm{MA}}$ & D & Bos 2 & 21,14 & 13,37 \\
\hline 253 & Molar $1_{\mathrm{MA}}$ & $\mathrm{S}$ & Bos 2 & 20,52 & 13,30 \\
\hline 263 & Molar $2 \mathrm{MA}$ & D & Bos 1 & 23,31 & 15,97 \\
\hline 207 & Molar $2_{\mathrm{MA}}$ & D & Bos 2 & 22,53 & 14,68 \\
\hline 254 & Molar 3 & D & Bos 1 & 34,39 & 15,86 \\
\hline 255 & Molar $3_{\mathrm{MA}}$ & $\mathrm{S}$ & Bos 2 & 33,27 & 14,79 \\
\hline 305 & Molar 3 & D & Bos 2 & 33,34 & 14,34 \\
\hline
\end{tabular}




$\begin{array}{llllllll}\text { Número } & \text { pieza } & \text { lado } & \text { Individuo } & \text { LM cuerpo } & \begin{array}{l}\text { A s art } \\ \text { anterior }\end{array} & \begin{array}{l}\text { A s art } \\ \text { posterior }\end{array} & \begin{array}{l}\text { Am } \\ 36\end{array} \\ 227 & \text { Axis } & & \text { Bos } 1 & 94,01 & 88,1 & 29,11 & 52,62 \\ \text { Axis } & & \text { Bos } 2 & & 77,91 & & \end{array}$

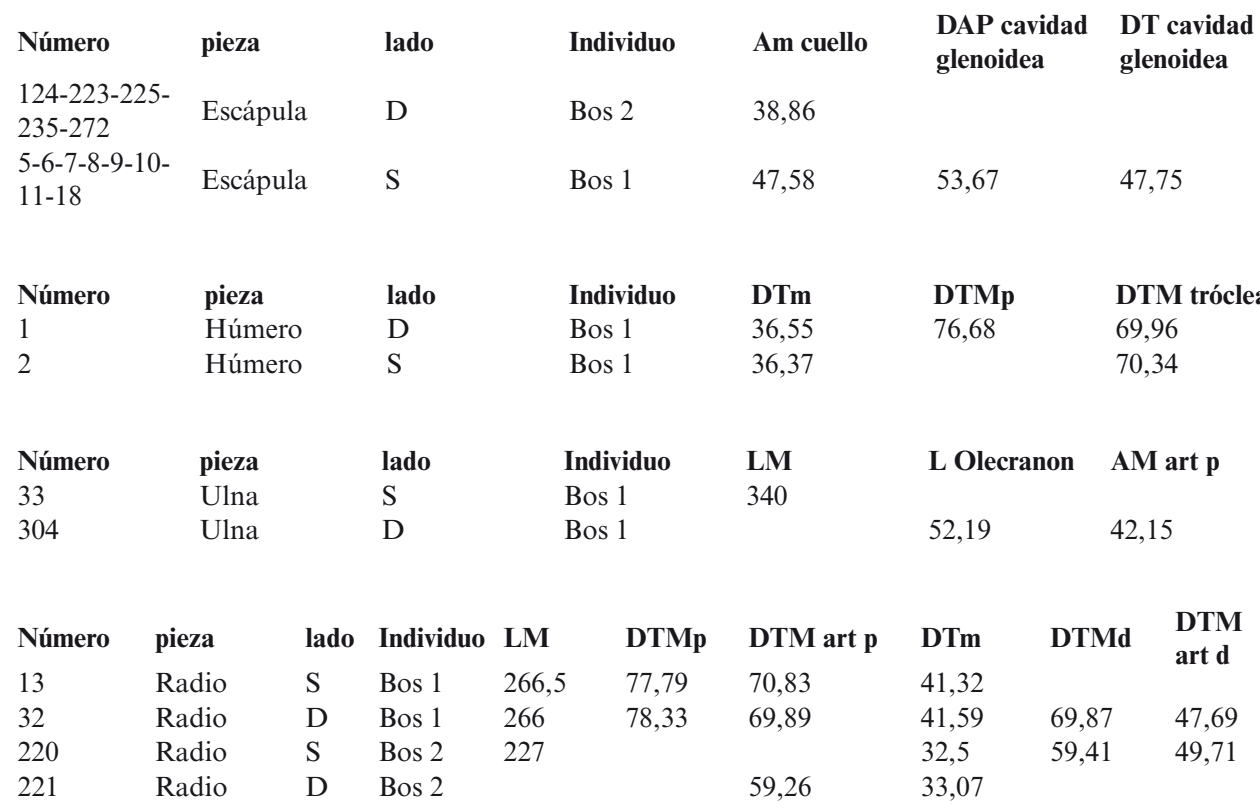

$\begin{array}{lllllll}\text { Número } & \text { pieza } & \text { lado } & \text { Individuo } & \text { LM } & \text { DTm } & \text { DAPm } \\ 102-119 & \text { Metacarpo } & \text { S } & \text { Bos 1 } & & 31,87 & \\ 106-123-177- & \text { Metacarpo } & \text { D } & \text { Bos 1 } & 183,5 & 31,9 & 22,63 \\ 275 & & & \end{array}$

\begin{tabular}{|c|c|c|c|c|}
\hline Número & pieza & lado & Individuo & DAP cavidad cotiloidea \\
\hline 164 & Pelvis & & Bos 1 & 49,44 \\
\hline
\end{tabular}

$\begin{array}{lllllll}\text { Número } & \text { pieza } & \text { lado } & \text { Individuo } & \text { DTMd } & \text { DTm } & \text { DAP cabeza } \\ 37 & \text { Fémur } & \text { D } & \text { Bos } 1 & 91,5 & 35,53 & 39,58 \\ 38 & \text { Fémur } & \text { S } & \text { Bos 1 } & & 35,42 & 39,57 \\ 112-174-180- & \text { Fémur } & \text { D } & \text { Bos } 2 & & 29,31 & \end{array}$

$\begin{array}{llllllll}\text { Número } & \text { pieza } & \text { lado } & \text { Individuo } & \text { LM } & \text { DTMp } & \text { DTMd } & \text { DAPMd } \\ 3 & \text { Tibia } & \text { S } & \text { Bos } 1 & 326 & & 58,05 & \\ 4-12-127 & \text { Tibia } & \text { D } & \text { Bos } 1 & 322,5 & 90,95 & 58,55 & 44,62\end{array}$




\begin{tabular}{|c|c|c|c|c|c|}
\hline Número & pieza & lado & Individuo & L lateral & L media \\
\hline 131 & astragalo & $\mathrm{S}$ & Bos 1 & 60,23 & 30,51 \\
\hline $\begin{array}{l}\text { Número } \\
114\end{array}$ & $\begin{array}{l}\text { pieza } \\
\text { tarso calcaneo }\end{array}$ & $\begin{array}{l}\text { lado } \\
\text { S }\end{array}$ & $\begin{array}{l}\text { Individuo } \\
\text { Bos } 1\end{array}$ & $\begin{array}{l}\text { LM } \\
120,65\end{array}$ & DTM \\
\hline 115 & tarso calcaneo & D & Bos 1 & & 40,24 \\
\hline
\end{tabular}

$\begin{array}{lllllllllll}\text { Número } & \text { pieza } & \text { lado } & \text { Individuo } & \text { LM } & \text { DTMp } & \text { DAPMp } & \text { DTm } & \text { DTMd } & \text { DAPMd } & \text { DAPm } \\ 34 & \text { Metatarso } & \text { S } & \text { Bos 1 } & 214 & & 41,74 & 26,8 & 52,06 & 34,42 & 26,3 \\ 35 & \text { Metatarso } & \text { D } & \text { Bos 1 } & 214 & 47,73 & 41,06 & 27,37 & & & 26,3\end{array}$

$\begin{array}{llllllll}\text { Número } & \text { pieza } & \text { lado } & \text { Individuo } & \text { LM } & \text { DTMp } & \text { DTmd } & \text { DTm } \\ 30 & \text { Falange 1 } & & \text { Bos 1 } & 55,19 & 27,34 & 27,93 & 24,24 \\ 31 & \text { Falange 1 } & & \text { Bos 1 } & & & & 25,1\end{array}$

\begin{tabular}{|c|c|c|c|c|c|c|}
\hline $\begin{array}{l}\text { Número } \\
129\end{array}$ & $\begin{array}{l}\text { pieza } \\
\text { Falange } 2\end{array}$ & $\begin{array}{l}\text { Individuo } \\
\text { Bos } 1\end{array}$ & LM & $\begin{array}{l}\text { DTMp } \\
29,34\end{array}$ & $\begin{array}{l}\text { DTmd } \\
25,96\end{array}$ & $\begin{array}{l}\text { DTm } \\
23,98\end{array}$ \\
\hline $\begin{array}{l}\text { Número } \\
132\end{array}$ & $\begin{array}{l}\text { pieza } \\
\text { Falange } 3\end{array}$ & lado & $\begin{array}{l}\text { Individuo } \\
\text { Bos } 1\end{array}$ & $\begin{array}{l}\mathbf{L M} \\
67,39\end{array}$ & & $\begin{array}{l}\text { L sup ventral } \\
66,36\end{array}$ \\
\hline
\end{tabular}

